\title{
PERBANDINGAN NOVEL LAIN ETA KARYA MOH. AMBRI \\ DENGAN DJEUMPA ATJEH KARYA H.M. ZAINUDDIN \\ (Kajian Struktural dan Etnopedagogik)
}

\author{
Witri Gustiani, Ruhaliah, Dedi Koswara \\ Departemen Pendidikan Bahasa Sunda FPBS UPI \\ Pos-el: witrigustiani@student.upi.edu, ruhaliah@upi.edu \\ dedi.koswara@upi.edu
}

\begin{abstract}
Abstrak
Penelitian ini bertujuan untuk mendeskripsikan perbandingan struktur cerita dari novel Lain Eta karya Moh. Ambri dan Djeumpa Atjeh karya H.M. Zainuddin, serta analisis mengenai nilai-nilai etnopedagogiknya. Metode yang digunakan adalah metode deskripsi dengan teknik kajian pustaka. Dua karya sastra ini sama-sama memiliki kesamaan dalam karakter utamanya, yaitu perempuan. Dua novel ini memiliki kesamaan tema, yakni kawin paksa. Teori yang digunakan dalam penelitian ini adalah perbandingan antar karya sastra daerah menurut Endraswara, fakta-fakta cerita Robert Stanton untuk kajian struktural, dan nilainilai etnopedagogik menurut Sudaryat.Pihak orang tua dari masing-masing karakter utama itu menginginkan agar anaknya menikah dengan lelaki pilihan, bukan dengan yang dicintai oleh anaknya. Konflik ini pada akhirnya membuat keseluruhan cerita berkembang dan mengarah pada akhir cerita yang berbeda. Dengan adanya penelitian ini diharapkan bisa menambah wawasan mengenai sastra perbandingan, serta perbandingan antar karya sastra daerah di Indonesia.
\end{abstract}

Kata Kunci: perbandingan, struktur,etnopedagogik

\section{COMPARISON OF NOVEL LAIN ETA BY MOH. AMBRI AND DJEUMPA ATJEH BY H.M. ZAINUDDIN (Structural and Etnhopedagogy Review)}

\begin{abstract}
The aims of this research is to describe about the structure comparison between the novel Lain Eta by Moh. Ambri and Djeumpa Atjeh by H.M. Zainuddin, and the analysis of ethnopedagogical values. These two novels have the same theme, named kawin paksa.The theology used in this research is comparison between literature region by Endraswara, the facts if story by Robert Stanton, and also etnhnopedagogy values by Sudaryat. The method in this research is description, and literature review. These two novels have the same main characters, there is the girl who can't marriage with their loves because the parents is not agree. Their parents wants to have a son-in-law by the men which parents choose, and the conflict was stared from this. This research hopes is can be add insight about comparative literature, and comparative literature region in Indonesia.
\end{abstract}

Keywords: comparative literature, structural, ethnopedagogy 


\section{PENDAHULUAN}

Dalam khazanah sastra Sunda, terdapat beberapa karya sastra hasil terjemahan dari bahasa lain. Di antarananya yaitu novel Parawan di Jalan Sepi karya Sir Arthur Conan Doyle yang diterjemahkan ke dalam bahasa Sunda oleh Bratakusuma dari jurul bahasa Inggris The Return of Sherlock Holmes; The Solitary Cyclist, atau Gadis Pengendara Sepeda. Selain itu, ada pula novel Bentang Aceh karya H.M. Zainuddin yang diterjemahkan oleh Moh. Ambri ke dalam bahasa Sunda. Dalam resensi bukunya, disebutkan bahwa novel ini bisa jadi satu-satunya karya sastra Aceh yang diterjemahkan ke dalam bahasa Sunda. Moh Ambri sendiri merupakan salah satu sastrawan Sunda yang populer, salah satu karyanya yaitu Lain Eta. Dua novel ini memiliki konflik atau persoalan yang hampir sama, yang jika diteliti lebih lanjut akan menghasilkan perbandingan terhadap persamaan dan perbedaannya.

Sastra perbandingan merupakan suatu metode untuk memeprluas penelitian sastra, tidak hanya berdasarkan suatu bangsa atau negara (Damono dalam Ruhaliah, 2015, hlm. 4). Ahli yang lain menyebutkan bahwa sastra perbandingan lebih terfokus pada interaksi dan kemiripan di antara dua sastra nasional atau lebih (Jost dalam Susanto, 2016, hlm. 30). Selanjutnya, istilah sastra perbandingan yaitu studi hubungan dua kesusastraan atau lebih (Wellek \& Warren, 2014, hlm. 46). Oleh karena itu, kajian sastra perbandingan akan lebih dalam sebab bahan penelitiannya lebih dari satu karya sastra. Menurut Endraswara (dalam Karlingga, 2015, hlm. 2) penelitian sastra perbandingan adalah penelitian yang tidak akan membosankan karena banyak hal yang bisa dibahas.

Sastra sebagai hasil atau gambaran dari kehidupan masyarakat bisa berhubungan dengan bagaimana kebudayaan dan latar belakang kehidupan lainnya ketika karya sastra itu ditulis.
Sastra bisa dianalisis lewat membedah isi cerita dan menghubungkannya dengan unsur-unsur di luar karya sastra yang nantinya akan dianalisis pula latar belakang pengarang dalam menulis karya sastranya. Menurut Koswara (2013, hlm. $10)$, sastra yang ditulis dalam kurun waktu tertentu erat kaitannya dengan normanorma serta adat-istiadat yang berkembang pada zamannya. Selanjutnya menurut Endraswara (2016, hlm. 5), antara corak budaya dan sastra ditentukan pula oleh pola hidup dan karakteristik wilayah yang berbeda.

Sastra perbandingan secara sederhana mempunyai beberapa fungsi untuk kehidupan sastra, di antaranya:

a. untuk membantu proses kreatif pengarang;

b. membantu para ahli sastra dalam menyusun sejarah sastra, serta agar tidak ada plagiarisme;

c. untuk mengetahui orisinalitas suatu karya sastra; dan

d. untuk meningkatkan kreativitas pengarang dalam menghasilkan karya (Endraswara, 2014, hlm. 105-106).

Salah satu karya sastra yang bisa dibandingkan itu di antaranya adalah novel Lain Eta karya Moh. Ambri dan Djeumpa Atjeh karya H.M. Zainuddin. Dua novel ini berasal dari dua daerah yang berbeda di Indonesia, yaitu Sunda dan Aceh. Dua daerah yang berbeda pulau dan berbeda kebudayaan ini ditulis dalam kurun waktu yang tidak terlalu jauh. Novel Lain Eta terbit pertama kali pada tahun 1934 oleh penerbit Balai Pustaka. Pernah pula diterbitkan oleh Rahmat Cijulang, namun yang menjadi bahan penelitian di sini adalah yang diterbitkan oleh penerbit Kiblat Buku Utama tahun 2011. Dalam pengantarnya, Muhtadin (Ambri, 2011, hlm. 5) menyebutkan bahwa dalam sajarah kesusastran Sunda, novel ini telah mendapatkan banyak penghargaan, yang semakin mengukuhkan Moh. Ambri sebagai maestro di dalam sastra Sunda. Moh. Ambri pernah menerjemahkan novel 
Djeumpa Atjeh ke dalam bahasa Sunda yang bukunya diterbitkan oleh Kiblat Buku Utama bulan Oktober tahun 2014 dalam judul Bentang Aceh. Djeumpa Atjeh sendiri pertama kali terbit oleh Balai Pustaka pada tahun 1926. Sedangkan yang menjadi bahan penelitian adalah terbitan Sultan Iskandar Muda, Medan pada tahun 1958.

Hasil penelitian sastra perbandingan ini diharapkan bisa mengetahui apa saja persamaan dan perbedaan dari dua novel tersebut. Menurut Dwi Susanto (2016, hlm. 30), dengan sastra bandingan, kajian persamaan dan pengaruh atau resepsi (hubungan kontak kebudayaan) akan lebih luas. Faktor apa saja yang menyebabkan dua karya sastra ini ditulis, yang erat kaitannya dengan keadaan zaman saat itu di daerah Sunda dan Aceh, khususna di negara Indonesia. Benedecto Crose (dalam Karlingga, 2015, hlm. 5), menyebutkan bahwa komparatif atau perbabandingan adalah kajian yang berupa eksplorasi perubahan (vicissitude), pergantian (alternation), pengembangan (development), dan perbedaan timbal balik antara dua karya atau lebih.

Karakter, alur, dan latar merupakan fakta-fakta cerita. Elemen-elemen ini berfungsi sebagai catatan kejadian imajinatif pada sebuah cerita. Jika dirangkum menjadi satu, semua elemen ini dinamakan 'struktur faktual' atau 'tingkatan faktual' cerita (Stanton, 2012, hlm. 22). Sedangkan tema merupakan aspek cerita yang sejajar dengan makna dalam pengalaman manusia; sesuatu yang menjadikan suatu pengalaman begitu diingat (Stanton, 2012, hlm. 36). Dalam novel ada yang disebut alur peristiwa kausal. Peristiwa kausal yaitu peristiwa atau kejadian yang menyebabkan atau mempunya dampak yang panjang dan berpengaruh terhadap isi cerita (Stanton, 2012, hlm. 26). Novel sendiri bisa menunjukan perkembangan satu karakternya, keadaan sosial yang rumit, hubungan beberapa karakter, dan kejadian-kejadian yang ada dalam tahun- tahun yang telah berlalu dengan rinci (Stanton, 2012, hlm. 90). Bisa saja kejadian itu tidak penting, tapi bisa menyebabkan perubahan atau berpengaruh terhadap isi cerita sampai tamat. Peristiwa kausal juga tidak dibatasi terhadap hal-hal yang sipatnya fisik, tapi bisa pula terhadap perubahan kebiasaankebiasaan, prinsip hirup, dll. (Stanton, 2012, hlm. 26).

Pendekatan yang akan dipakai dalam penelitian ini yaitu struktural dan etnopedagogik. Analisis struktural bertujuan untuk membongkar dan menjelaskan dengan teliti serta mendalam terhadap hal-hal yang erat kaitannya dengan hubungan unsur-unsur dalam karya sastra (Teeuw, 2015, hlm. 106). Sedangkan yang disebut etnopedagogik adalah praktek pendidikan berdasarkan kearifan lokal serta nilai-nilai norma yang menjadi standar kehidupan (Rustaman dalam Albaiti, 14, 2015).

\section{METODE}

Penelitian ini termasuk pada penelitian kualitatif terhadap objek sastra. Penelitian kualitatif menurut Moleong (2012, hlm. 6) adalah penelitian yang mempunyai maksud untuk memahami semua kejadian yang dialami subjek yang dijelaskan dengan cara mendeskripsikannya dengan kalimat dan bahasa dalam suatu konteks alamiah serta memanfaatkan berbagai metode ilmiah.

Sebelum menentukan teori dan metode dalam menganalisis karya sastra, diperlukan pendekatan terhadap karya sastra sebagai objek penelitian yang akan dianalisis. Pendekatan ini berfungsi untuk meneliti objek penelitian. Dalam penelitian ini, digunakan pendekatan objektif atau struktural. Pendekatan objektif dipilih karena mempunyai tujuan untuk mengetahui objek dari segi strukturnya. Semi dalam Koswara (2013, hlm. 8) memberikan batasan tentang pendekatan objektif ngawatesanan ini, bahwa penelitian secara objektif itu lepas dari pengarang dan pembaca. Oleh sebab 
itu, melalui pendekatan objektif atau diistilahkan struktural diharapkan bisa mencapai penemuan-penemuan baru untuk perkambangan dalam dunia sastra Sunda.

Metode penelitian adalah cara yang digunakan peneliti dalam mengumpulkan data penelitian. Metode bisa berupa angket, wawancara, observasi, tes, dan dokumentasi (Arikunto, 2013, hlm. 203). Sedengkan menurut Sugiyono (2015, hlm. 3) penelitian adalah cara ilmiah untuk mendapatkan data yang mempunyai tujuan dan manfaat tertentu. Metode yang dipakai dalam penelitian ini yaitu metode deskripsi dengan menggunakan teknik studi pustaka. Penelitian deskripsi yaitu suatu penelitian yang paling mendasar. Untuk mendeskripsikan atau menggambarkan fenomena-fenomena yang aya, baik fenomena yang bersipat alamiah maupun yang dibuat manusia (dalam Sukmadinata, 2015, hlm. 72). Selain itu, metode ini membahas bentuk, aktivitas, karakteristik, perubahan, hubungan, persamaan dan perbedaan serta fenomena lainnya yang sesuai dengan sastra perbandingan. Dalam penelitian ini menggunakan karya sastra sebagai objeknya, dengan metode deskripsi untuk menganalisis penelitian terhadap sumbersumber data.

\section{HASIL DAN PEMBAHASAN}

Maspuroh (2015, hlm. 234) menyebutkan bahwa suatu kaarya sastra yang baru, bisa ditulis berdasarkan karya sastra yang telah lebih dulu ada, karena sebuah karya sastra bisa mendapatkan pengaruh dari karya sebelumnya. Analisis tentang perbandingan dalam penelitian ini, yaitu analisis struktural. Unsur-unsur yang termasuk dalam fakta cerita menurut Robert Stanton yaitu karakter, alur, dan latar, yang dalam penelitian ini ditambah pula dengan tema. Unsur-unsur tersebut mempunyai fungsi sebagai catatan imajinatif terhadap isi carita. Unsur-unsur itu disebut juga struktur faktual atau tingkatan faktual. Struktur faktual cerita merupakan salah satu cara untuk menjelaskan bagaimana detail-detail cerita diorganisasikan. Untuk bisa mengapresiasi struktur faktual cerita, pembaca harus percaya terhadap isi carita.

\section{Perbandingan Struktur Novel Lain Eta karya Moh. Ambri}

Analisis tentang perbandingan dalam penelitian ini, yaitu analisis struktural. Unsur-unsur yang termasuk dalam fakta cerita menurut Robert Stanton yaitu karakter, alur, dan latar, yang dalam penelitian ini ditambah pula dengan tema. Unsur-unsur tersebut mempunyai fungsi sebagai catatan imajinatif terhadap isi carita.

\section{Karakter Utama}

Menurut Stanton (2012, hlm. 33) yang disebut karakter utama adalah karakter yang terikat dengan semua kejadian dalam isi cerita. Alasan mengapa seorang karakter melakukan suatu hal adalah karena adanya 'motivasi'. Motivasi spesifik seorang karakter sebab suatu reaksi spontan, yang bisa saja karena tidak disengaja, yang dijelaskan dalam adegan atau dialog. Motivasi dasar merupakan aspek umum dari seorang karakter yang menyebabkan karakter itu ada dalam alur cerita.

Neng Eha dan Sitti Saniah adalah karakter utama dari masing-masing novel. Oleh orang-orang di sekitarnya, mereka sangat dihargai, baik karena melihat orang tua mereka, maupun karena sifat fan tingkah laku mereka sendiri. Dari 7 bab dalam novel Lain Eta, karakter Neng Eha tidak terlalu dibahas dalam bab "Lain Kupu" biarpun memang masalah yang ada menyangkut dirinya. Begitu pula dalam novel Djeumpa Atjeh, karakter Sitti Saniah ketika kedua orang tuanya membahas tentang perjodohannya dalam bab "Ibu dan Bapa Bermufakat" pun juga tidak disebut-sebut. Hal ini menyebabkan adanya motif yang sama dari dua karya ini, yaitu kedua orang tua yang tidak 
mempedulikan perasaan anaknya dalam masalah perjodohan.

Kehidupan sehari-harinya pun hampir sama, terutama dalam hal tidak pernah melawan orang tua. Dalam sedikit perlawanannya pun hanya ada menjelang akhir cerita. Bedanya Neng Eha merupakan anak tunggal dan sedikit dimanja orang tuanya, sedangkan Sitti Saniah merupakan anak bungsu, namun dari kecil ia sudah dididik mandiri oleh orang tuanya. Karena dua novel ini ditulis dalam kurun waktu yang tidak terlalu jauh, serta sama-sama pertama kali diterbitkan oleh Balai Pustaka. Oleh karena itu, sistem pembelajarannya pun masih dalam sistem Hindia Belanda. Tetapi yang dijelaskan hanya Neng Eha, yakni ia pernah bersekolah di H.I.S. Sitti Saniah tidak dijelaskan apakah pernah mengenyam pendidikan atau tidak, tapi ia sendiri mempunyai pribadi yang baik dan cita-cita yang luhur.

\section{Karakter Tambahan}

Perbedaan yang paling terlihat yaitu dari segi jumlah karakter. Dalam novel Lain Eta laki-laki yang diceritakan dekat dengan Neng Eha ada tiga orang, sedangkan dalam novel Djeumpa Atjeh ada dua. Nasib laki-laki yang pertama (Mahmud dan Nya' Amat) sama, setelah lamaran diterima, tidak lama kemudian dari pihak orang tua perempuan mendadak membatalkannya. Dalam menyampaikan lamarannya, baik Mahmud maupun Nya' Amat sama-sama dibantu oleh pihak lain. Mahmud dibantu oleh Raden Kartakusumah, kerabat jauhnya yang cukup mengenal orang tua Neng Eha. Sedangkan Nya' Amat dibantu oleh Engku Sulaiman beserta istrinya. Engku Sulaiman sendiri sudah dianggap orang tua oleh Nya' Amat, dan sangat mendukung agar Nya' Amat bisa bersatu dengan Sitti Saniah.

Pihak orang tua dari kedua karakter utama dalam masing-masing novel sama-sama ingin memiliki menantu dari kalangan atas, yakni bangsawan.
Juragan Kalipah, ayah Neng Eha ingin agar anaknya menikah dengan laki-laki turunan raden, sedangkan Ibu Saniah ingin anaknya menikah dengan bangsawan. Perbedaannya, pihak orang tua yang otoriter dari novel Lain Eta yaitu ayah Neng Eha, Juragan Kalipah, sedangkan dalam novel Djeumpa Atjeh yaitu pihak Ibu Saniah.

Adanya motif karakter yang membantu untuk lamaran ini menjadi salah satu motif yang sama, khas, dan kuat, dari masing-masing novel. Perbedaannya adalah Raden Kartakusumah masih memiliki kekerabatan dengan Mahmud. Sedangkan Engku Sulaiman dan istrinya, membantu Nya' Amat karena melihat kecocokan keduanya. Sama-sama memiliki cita-cita yang luhur terhadap bangsanya. Baik Raden Kartakusumah maupun Engku Sulaiman sama-sama mempunyai pribadi yang bijaksana, karena ketika lamaran itu ditolak, mereka tidak merasa ingin membalas sakit hati atau lainnya.

Selanjutnya, adanya karakter dukun, yang membedakan adalah karakter yang meminta tolong. Dalam novel Lain Eta, karakter yang meminta tolong pada dukun adalah Neng Eha, sang karakter utama. Ia diantar oleh Uwanya ketika mendatangi rumah Mang Okom. Sedangkan $\mathrm{n}$ dalam Djeumpa Atjeh, karakter yang meminta bantuan dukun adalah Ibu Saniah, yang menginginkan agar anakna bisa menuruti keinginan orang tuanya untuk melupakan Nya' Amat dan menikah dengan Teuku Banta Raman.

Juragan Teja adalah satu-satunya orang yang bisa dipercaya oleh Neng Eha, sedangkan Sitti Saniah memilih neneknya untuk diajak berkelu-kesah tentang nasib dirinya.

\section{Alur}

Alur merupakan rangkaian peristiwa dalam suatu cerita. Peristiwa kausal yaitu peristiwa atau kejadian yang menyebabkan atau mempunya dampak yang panjang dan berpengaruh terhadap 
isi cerita (Stanton, 2012, hlm. 26). Novel sendiri bisa menunjukan perkembangan satu karakternya, keadaan sosial yang rumit, hubungan beberapa karakter, dan kejadian-kejadian yang ada dalam tahuntahun yang telah berlalu dengan rinci (Stanton, 2012, hlm. 90). Bisa saja kejadian itu tidak penting, tapi bisa menyebabkan perubahan atau berpengaruh terhadap isi cerita sampai tamat. Peristiwa kausal juga tidak dibatasi terhadap hal-hal yang sipatnya fisik, tapi bisa pula terhadap perubahan kebiasaankebiasaan, prinsip hirup, dll. (Stanton, 2012, hlm. 26).

Novel Lain Eta terdiri dari 7 bab dalam 85 halaman, sedangkan novel Djeumpa Atjeh dua kali lebih banyak, yakni 19 bab dalam 150 halaman. Tapi meskitpun begitu, masalah yang ditemukan lebih banyak dan lebih rapat dalam novel Lain Eta. Karena hanya terdiri dari 85 halaman, maka alur dan perubahan-perubahan kejadiannya lebih cepat namun sedikit deskripsi. Dibandingkan dengan Lain Eta, novel Djeumpa Atjeh memiliki jumlah halaman yang lebih banyak, namun perubahanperubahan dalam setiap kejadiannya lebih lama dan juga deskripsi-deskripsi yang panjang sebagaimana ciri khas novelnovel melayu dengan teknik cerita berbingkai.

\section{Tema}

Tema merupakan aspek cerita yang sejaajr dengan makna dalam pengalaman manuisa; hal yang menyebabkan suatu pengalaman dapat diingat lebih lama. Tema berdasarkan aspek-aspek dalam kehidupan, yang menyebabkan adanya nilai-nilai kehidupan yang nampak dari dalam cerita. Dengan adanya tema, isi cerita menjadi terfokus, dan mempunyai dampak. Cara yang efektif agar bisa mengetahui tema dari suatu cerita adalah dengan cara memahami setiap konflik yang ada dalam isi cerita (Stanton, 2012, hlm. 36).
Motif kawin paksa terlihat jelas dalam dua novel ini. Dari mulai analisis dari karkaterorang tua dari karakter utama yang bersikap otoriter, menunjukan bahwa mereka lebih mementingkan urusan harkat dan amartabat daripada perasaan anaknya. Seperti yang diinginkan oleh Juragan Kalipah, ayah Neng Eha, bahwa ia menginginkan agar anaknya menikah dengan laki-laki yang sama-sama turunan raden. Emas harus bersanding dengan emas juga, begitu pun sebaliknya. Karena jika tidak begitu, maka akan hilang sifat dari keemasannya, hilang keradenannya.

Motif diam-diam dalam melakukan suatu hal pun sama-sama terlihat dalam dua novel ini. Latar belakang sosial dan budaya dari kedua novel ini sama-sama menganut kesopanan dalam hubungan antara laki-laki dan perempuan yang belum terikat dalam pernikahan. Selain itu, jika kedua orang tua mereka tahu, sudah pasti akan kena marah dan hukuman. Ayah Neng Eha adalah seorang Kalipah Kota, pasti akan malu dan marah jika mendapati anaknya sedang berduaan dengan laki-laki yang bukan muhrimnya. Begitu pula dengan yang terjadi pada Sitti Saniah, hukum adat Aceh bersumber dari hukum Islam, di mana antara laki-laki dengan perempuan diharamkan untuk berdekatan apalagi hanya berduaan saja.

Motif latar belakang keluarga dan pihak orang tua dari karakter laki-laki juga berpengaruh terhadap ditolaknya lamaran mereka oleh orang tua perempuan. Seperti yang telah dijelaskan di atas, bahwa pihak orang tua perempuan menginginkan lakilaki yang sepadan dengannya. Namun pada kenyataannya, baik Mahmud maupun Nya' Amat berasal dari keluarga yang biasa-biasa saja. Sederhana namun mengedepankan kemajuan anak lakilakinya dalam bidang pendidikan. Orang tua Mahmud hanya disebutkan namanya saja, dan apa pekerjaannya. Sedangkan orang tua Nya' Amat diceritakan ketika ia akan pergi merantau untuk sekolah. Ibunya yang terbiasa bersama-sama 
dengan anaknya menjadi sedih dan kehilangan, padahal kepergian Nya' Amat adalah untuk menuntut ilmu. Hal seperti ini banyak terjadi dalam novel-novel Balai Pustaka, di mana orang tua terutama pihak ibu, tidak menginginkan anaknya untuk merantau demi bersekolah karena tidak ingin berpisah dalam jarak yang jauh dan dalam wajtu yang lama.

Meskitpun sama-sama pernah bersekolah, namun hal itu tidak menjadi bahan pertimbangan agar lamaran mereka diterima sampai menikah. Saat melamar Neng Eha, Mahmud tinggal beberapa bulan lagi lulus dari sekolahnya di Batavia, sedangkan Nya' Amat sudah bekerja di kantor gubernamen (kompeni). Tapi hal itu pun juga tidak berpengaruh, karena yang orang tua pihak perempuan inginkan adalah turunan raden dan bangsawannya. Hal ini juga sitentang oleh ibunda Neng Eha, Nyi Emot, bahwa sikap otoriter itu lebih memntingkan turunan daripada yang lainnya, seakan-akan lebih baik laki-laki yang buruk rupa tapi raden daripada laki-laki rupawan namun orang biasa.

\section{Perbandingan Nilai-Nilai Etnopedagogik dalam novel Lain Eta karya Moh. Ambri dan Djeumpa Atjeh karya H.M. Zainuddin}

Etnopedagogik, adalah praktek pendidikan yang berdasarkan pada kearifan lokal, serta nilai-nilai etnis yang menjadi standar perilaku (Rustaman dalam Albaiti, 14, 2015). Etnopedagogik Sunda memiliki tujuan untuk menghasilkan manusia yang unggul atau jalma nu masagi. Sedangkan manusia yang masagi itu adalah manusia yang berpengetahuan dan berpengalaman. Orang seperti itu disebut pula orang yang legok tapak genteng kadek. Tidak menutup kemungkinan bahwa orang seperti itu memiliki visi dan misi untuk kehidupan di masa depan dengan sanagt baik (Sudaryat, 2014, hlm. 124).

Menurut Suryalaga (dalam Sudaryat, 2014, hlm. 124-125), karena memiliki pengalaman lahir dan batin, tujuan etnopedagogik Sunda adalah untuk menciptakan Catur Jatidiri Insan sebagai manusa unggul (maung). Catur Jatidiri Insan terdiri dari nilai-nilai seperti di bawah ini.

a. Taat Beragama (spiritual quotient), mempunyai perilaku yang sesuai dengan IMTAQ.

b. Berilmu Tinggi (intelectual quotient), kualitas sumber daya manusia yang cerdas, dan bisa bersaing.

c. Luas Budayanya (emotional quotient), mempunyai wawasan yang luas, bijaksana, tidak gagap budaya, bisa menghargai multietnis dan multikultur.

d. Terampil Bekerja (actional quotient), kualitas dari proses yang sinergik antara IQ, EQ, dan SQ, teliti, kreatif, dan inovatif.

Dalam prosesna, etnopedagogik Sunda juga terdapat dalam wujud triSILAS, yaitu silih asih, silih asah, dan silih asuh, yang selanjutnya bisa mengantarkan seseorang menuju manusia yang masagi (cageur, bageur, bener, pinter, singer) (Sudaryat, dalam Sudaryat, 2014, hlm. 128).

Hasil dari analisis tentang nilai-nilai etnopedagogik dalam novel Lain Eta karya Moh. Ambri adalah sebagai berikut.

\section{Taat Beragama (spiritual quotient).}

Dua novel ini mempunyai latar belakang agama yang kuat. Dalam novel Lain Eta, ayah Neng Eha adalah seorang Kalipah Kota, yang sudah pasti sangat menjaga anakna dengan cara mendidiknya dari kecil tentang hukum-hukum agama Islam. Begitu pun dalam novel Djeumpa Atjeh, seperti yang disebutkan dalam novelnya sendiri, bahwa sumber hukum adat di Aceh adalah hukum Islam. Maka dari itu, pada aturan yang dipakai seharihari pun tidak jauh dari hukum-hukum Islam, termasuk bagaimana hubungan seorang perempuan dengan seorang lakilaki yang belum terikat pernikahan. Seperti dalam kutipan cerita di bawah ini. 
"Keur diwurukan ku ramana, diseuseul, diseukseukan, disingsieunan ku carita-carita cék kitab, tara ngalawan, tara némbalnémbal acan, tungkul mando masing sababaraha jongjonan ogé. (hlm. 63)"

Neng Eha sebagai karakter utama dari masing-masing novel mempunyai sifat yang baik dan penurut. Tidak sedikit pun berani melawan kedua orang tuanya. Hal ini menunjukan adanya rasa hormat dan patuh yang tinggi. Hal ini terlihat pada awal-awal cerita hingga pertengahan. Sedangkan dalam novel Djeumpa Atjeh karya H.M. Zainuddin adalah sebagai berikut. Tokoh Nya' Amat paling terlihat menonjol karena ia senantias menjaga sopan santunnya kala bertemu dengan Sitti Saniah maupun dengan orang tua. Hukum adat Aceh yang bersumber dari hukum Islam sudah dipadukan dengan baik olehnya. Seperti dalam kutipan cerita di bawah ini.

"Tiba-tiba pemuda itu menekankan dadanja dengan tangan kirinja, serta berkata pula kepada dirinja sendiri dengan suara jang amat lain dari pada tahadi itu : „Ah, hati setan! Apa gunanja kuketahui nama orang? Lain tidak akan merusakkan pikiran sadja. Djika aku berkenalan dengan dia dan kemudian barangkali djatuh tjinta kepadanja, sedang agaknja aku bukan djodohnja atau ta' dapat berdjodoh dengan dia, apakah djadinja aku ini? Sambil berpikir demikian diambilnjalah sepotong rokok dari dalam sakunja, lalu dipasangnja. Kitabnjapun dibatjanja pula, akan pelengah pikirannja jang terharu-biru itu.(hlm. 12)"

Dari kutipan di atas, dapat diketahui bahwa ketika pertama kali bertemu dengan Sitti Saniah, sikap Nya' Amat sangat sopan. Ia menjaga pandangan, pikiran dan hatinya agar tidak berbuat hal yang melanggar adat. Apalagi saat itu hanya ada mereka berdua di dalam gerbong kereta tersebut.
Berilmu Tinggi (intelectual quotient).

Meskipun tidak terlalu diceritakan dalam isi cerita, tokoh laki-laki (Mahmud dan Nya' Amat) pernah merasakan bersekolah di sekolah Belanda pada saat itu. Hal ini menunjukan adanya keinginan yang maju dan tekad yang kuat akan kepentingan menyenyam pendidikan demi menunjang kehidupan yang lebih baik. Karena pernah bersekolah dan banyak berinteraksi dengan orang-orang baru, maka keduanya tidak gagap budaya. Mereka bisa menerima perbedaanperbedaan yang bersumber dari latar belakang bangsa dan negara. Seperti dalam kutipan cerita di bawah ini.

"Kacaritakeun Mahmud geus di Batawi deui sakola. Ti barang datang tara ngagedékeun ulin, sabab kana samen panutup témpona ngan kari opat bulan deui. (hlm. 21)"

Sedangkan dalam novel Djeumpa Atjeh, meskipun tidak diceritakan pernah bersekolah, namun Sitti Saniah memiliki keinginan yang tinggi akan kemajuan bangsanya. Hal ini menunjukan bahwa ia berpikiran maju dan pribadi yang kritis. Hal ini pulalah yang menimbulkan niat untuk bisa mewujudkan keinginannya itu bersama-sama dengan Nya' Amat. Terlebih Nya' Amat sendiri memang seorang yang aktif di organisasi dan punya banyak gagasan-gagasan yang tinggi.

"Dalam hal pergerakan 'umum ia mendjadi lid dari N.I.P. Buah pikirannja sangat diindahkan dan dihargai orang. (hlm. 39)"

Karena memiliki wawasan dan keberanian, Nya' Amat banyak berkecimpung di organisasi hingga menjadi ketua. Hal ini menunjukan bahwa ia memiliki ilmu yang tinggi dan memanfaatkan ilmu itu dengan sebaikbaiknya.

Luas Budayanya (emotional quotient).

Dalam novel Lain Eta, perilaku yang dianggap luas budayanaya seperti dalam kutipan cerita di bawah ini. 
"Pukul lima geus kencling indit, beunang ngaginding, tara-tara ogé dikopéah - biasana buburundulan harita mah maké, da boga kopéah buludru hideung. Dasina weuteuh, sutra gilap, surup kana raksukan sérse. Kerah bodas mani nyacas, kaméjana gading ngora. Ari lancingana nyéta arék maén ténnis, lancingan laken gading; sapatuna wungu ngora, hérang ngagenclang, da meunang nyemir. Melenghir nyesep sigarét tjap Onta. Séla karéta mesin ditilaman ku saputangan bodas, bisi kotor kana lancingan. Anu sakitu kéwesna mah ku nu teu wawuh moal dinyanaan murid K.W.S, tangtu disangka satiden. (hlm. 25)"

Mahmud yang mengenakan pakaian seperti yang diceritakan tersebut menunjukan bahwa ia senang memakainya. Ia tidak akan berani memakainya apabila tidak senang dan tahu terhadap cara memakainya, yang menunjukan adanya wawasan dan pengetahuan mengenai cara berpakaian tersebut.

Sedangkan dalam novel Djeumpa Atjeh, karena telah mengenyam pendidikan dan bekerja di kantor gubernamen, tentu saja Nya' Amat paham akan hal ini. Dengan luasnya wawasan, ia bisa bertukar pendapat dengan orang lain tanpa menimbulkan pertikaian dan keributan. Menghargai perbedaan pendapat dengan kepala dingin. Seperti dalam kutipan di bawah ini.

"Telah lima bulan lamanja Nja' Amat tinggal di Kutaradja. Dalam pada itu banjaklah sudah sahabat kenalannja. Ia telah mendjadi lid Juliana Club. Pergaulannja amat baik dengan pemuda-pemuda Atjeh demikian djuga dengan bangsa lain. Sekalian orang suka kepadanja. Hampir setiap petang ia berdjalan-djalan sekeliling kota, atau berkereta angin dengan kawankawannja! (hlm. 39)

Seseorang yang memiliki wawasan yang luas tentang kebudayaan tentu akan bersikap terbuka terhadap perbedaan dari berbagai macam budaya yang ia temui. Begitu pula dengan Nya' Amat sesuai dengan kutipan cerita di atas.

\section{Terampil Bekerja (actional quotient)}

Keinginan untuk terus belajar dapat mengalahkan hambatan apapun termasuk dari di mana tempat belajar itu. Hal ini pulalah yang diatasi dengan baik oleh Sitti Saniah. Ia belajar berbagai keterampilan untuk perempuan di rumah seorang saudagar bernama Engku Sulaiman. Begitu pun dengan Nya' Amat, ia bisa terampil dalam bekerja di kantor, juga dalam urusan organisasi yang sama-sama ia tekuni. Seperti dalam kutipan di bawah ini.

"Pada keesokan harinja petjah chabar sudah, bahwa ta' lama lagi akan terdiri sebuah cursus keradjinan rumah tanggal untuk gadis 2 di Kutaradja. Buah pikiran itu terbit dari engku Suleiman laki isteri, serta dibantu dan disokong oleh Nja' Amat. Tentang derma Nja' Amat jang mula-mula $f$ 100,- - itu tidak lupa disiarkan orang, dengan pengharapan, siapa lagi jang sudi berbuat demikian untuk keperluan bangsanja? (hlm. 41)"

Nya' Amat tidak ragu untuk berinovasi demi kemajuan bangsa yang ia mimpikan. Kemajuan yang didukung penuh oleh orang-orang di sekitarnya termasuk Sitti Saniah. Hal ini menunjukan bahwa ia sudah berpikir ke depan dan telah menyusun rencana agar keinginannya terwujud.

Dua novel ini sama-sama menceritakan hubungan sepasang mudamudi yang baru merasakan jatuh cinta. Bagaimana mereka saling merasakan kerinduan yang dalam manakala berjauhan atau sudah lama tidak bertemu, sampai akhirnya menimbulkan sebuah gagasan ingin bisa hidup bersama selamanya. Perbedaannya terletak pada bagaimana cara mereka membangun hubungan tersebut. Dalam novel Lain Eta, Neng Eha dan Mahmud seringkali 
bertemu dengan jalan diam-diam, sedangkan dalam novel Djeumpa Atjeh, Sitti Saniah dan Nya' Amat menjalaninya dengan keterbukaan kepada orang tuanya. Namun meskipun begitu, komunikasi yang berlangsung lebih sering menggunakan surat-menyurat. Dengan adanya hubungan jarak jauh seperti ini, mereka bisa saling menjaga dari kejauhan dan saling melatih agar sama-sama sabar sampai akhirnya bisa melepas rindu ketika bertemu.

Baik di daerah Sunda maupun di daerah Aceh sama-sama mempunyai aturan dan kebiasaan yang dekat dengan agama. Bagi masyarakat Sunda sendiri memang pada umumnya dianggap sebagai muslim, walaupun tentu saja tidak semua dan bahkan nenek moyangnya pun tidak langsung beragama Islam. Berbeda dengan Aceh yang sampai mempunyai julukan Serambi Mekah, karena dianggap provinsi dengan masyarakat yang sangat taat pada aturan agama, terutama karena telah masuk pada aturan adat mereka. Tapi tentu saja masing-masing mempunyai nilai-nilai kearifan lokal dari kebudayaanananya masing-masing. Indonesia sebagai negara yang kaya akan suku bangsa, adat-istiadat, bahasa daerah dan kebudayaan lainnya, tentu saja sangat berpotensi mengembangkan nilai-nilai luhur tersebut ke dalam pembelajaran kehidupan sehari-hari. Dengan adanya standar perilaku dari masing-masing kebudayaan itu menyebabkan manusia Indonesia mempunyai ciri khas masingmasing yang erat kaitannya dengan persatuan dan kesatuan antarsuku bangsa.

\section{SIMPULAN}

Setelah menganalisis novel Lain Eta karya Moh. Ambri dan Djeumpa Atjeh karya H.M. Zainuddin, ditemukan bagaimana struktur cerita dari masingmasing novel. Selain itu, setelah menemukan struktur cerita lalu dibandingkan. Perbandingan ini tentu saja menghasilkan kesamaan dan perbedaan di antara keduanya. Hampir setiap struktur cerita memiliki kesamaan dan perbedaan. Hal ini sangat menarik mengingat dua novel ini berbeda daerah asal dan tentu saja latara belakang kebudayaannya. Namun jika dilihat dari tahun terbitan awal keduanya, memang tidak terlalu jauh. Selain itu, dua novel ini merupakan novel yang terbit oleh Balai Pustaka, di mana sebagai penerbit nomor satu saat itu Balai Pustaka memiliki wewenang dan aturan yang mengikat akan isi cerita yang ditulis oleh pengarang. Alasan utama mengapa dua karya sastra ini dibandingkan adalah karena adanya beberapa motif cerita yang sama, sekaligu menganding perbedaannya pula. Selain itu, karena masing-masing berasal dari daerah yang berbeda, maka akan sangat menarik jika menemukan kesamaan tersebut. Adanya perbedaan itu sudah diawali dari perbedaan daerah asal dan juga latar belakang kebudayaan, yang setelah dianalisis ternyata memiliki kesamaan sekaligus perbedaan yang hampir serupa. Novel Lain Eta karya Moh. Ambri ditulis dalam bahasa Sunda dan tentu saja membawa latar belakang kehidupan masyarakat Sunda di daerah Cianjur, Jawa Barat. Sedangkeun novel Djeumpa Atjeh karya H.M. Zainuddin menggunakan bahasa Melayu tinggi dan latar belakang ceritanya di daerah Kutaraja, Nanggroe Aceh Darussalam. Dari satu kesamaan pada dua novel ini, selanjutnya semakin bermunculan kesamaan pada motif-motif yang lain. Hal ini tentu saja dengan menggunakan struktur cerita agar sistematis. Karakter utama keduanya sama-sama perempuan (Neng Eha dan Sitti Saniah), menjadi salah satu aspek yang sangat penting untuk dibandingkan mengingat nasib dan kehidupan keduanya sama-sama terkekang oleh aturan lama yang dipegang orang tuanya. Ditambah lagi dengan karakter pada diri masing-masing, yang berhubungan erat dengan pola asuh kedua orang tua mereka. Motif pada bagian akhir ceritanya pun juga sangat penting, di mana 
setelah bertahannya kesamaan alur pada beberapa bab, diakhiri ending yang lebih dramatis pada Djeumpa Atjeh.

Hal yang menarik adalah tema kawin paksa yang dihubungkan dengan nilainilai etnopedagogik. Sebagaimana disebutkan di atas bahwa etnopedagogik adalah pembelajaran yang bersumber dari kearifan lokal, maka dalam konteks perbandingan dari dua karya sastra ini pun tidak kalah menarik. Tema kawin paksa tentu saja suatu tema yang setidaknya mengandung konflik yang menuai perlawanan baik secara langsung maupun tidak langsung dalam isi cerita, begitu pula dalam dua novel ini. Hal ini justru menarik untuk dihubungkan dengan nilai-nilai etnopedagogik di masing-masing daerah. Bagaimana mereka menghadapi kenyataan hidup yang demikian dengan tetap menjaga norma-norma adat yang berlaku dan tetap menjadi pribadi-pribadi yang menjaga norma-norma tersebut. Karena selalu ada hikmah dan bahan pembelajaran dari setiap permasalahan dalam kehidupan, yang dalam konteks ini adalah permasalahan yang ditemukan dalam karya sastra.

\section{PUSTAKA RUJUKAN}

Albaiti. 2015. Kajian Kearifan Lokal Kelompok Budaya Dani Lembah Baliem Wamena Papua. Jurnal Pendidikan Nusantara Indonesia Vol. 1 No. 1 2015. Jayapura: Universitas Cendrawasih. www.fkip.unismuh.ac.id/-jurnal

Arikunto, S. 2013. Prosedur Penelitian: Suatu Pendekatan Praktik. Jakarta: Rineka Cipta.

Ambri, Moh. 2011. Lain Eta. Bandung: Kiblat Buku Utama.

Endraswara, Suwardi. 2014. Metodologi Penelitian Sastra Bandingan. Jakarta: Bukupop.

Endraswara, Suwardi. 2016. Metodologi Penelitian Ekologi Sastra Konsep, Langkah, dan Penerapan.
Yogyakarta: CAPS (Center for Academic Publishing Service).

Karlingga, E. 2015. Analisis Perbandingan Nilai Budaya Novel Mendayung Impin karya Reyhan M. Abdurrohman Dengan Novel Negeri 5 Menara Karya A. Fuadi. Artikel E -Journal Tanjungpinang: Universitas Maritim Raja Ali Haji.

Koswara, Dedi. 2013. Racikan Sastra. Jurusan Pendidikan Bahasa Daerah, FPBS UPI.

Moleong, Lexy J. 2012. Metodologi Penelitian Kualitatif. Bandung: PT. Remaja Rosdakarya.

Ruhaliah. 2015. Sastra Bandingan. Bandung: Departemen Pendidikan Bahasa Daerah.

Sudaryat, Yayat. 2014. Wawasan Kesundaan. Jurusan Pendidikan Bahasa Daerah Fakultas Pendidikan Bahasa dan Sastra Universitas Pendidikan Indonesia.

Sukmadalamta, Nana Syaodih. 2015. Metode Penelitian Pendidikan. Bandung: Remaja Rosdakarya.

Susanto, Dwi. 2016. Pengantar Kajian Sastra. Yogyakarta: CAPS (Center for Academic Publishing Service).

Stanton, Robert. 2012. Teori Fiksi.Yogyakarta: Pustaka Pelajar.

Teeuw, A. 2015. Sastra dan Ilmu Sastra. Bandung: Pustaka Jaya.

Wellek, Rene \& Austin Warren. 2014. Teori Kesusastraan. Jakarta: PT Gramedia Pustaka Utama.

Zainuddin, H.M. 1958. Djeumpa Atjeh. Pustaka Sultan Iskandar Muda Medan.

\section{UCAPAN TERIMA KASIH}

Penulis sangat berterima kasih kepada dosen pembimbing yaitu Dr. Hj. Ruhaliah, M.Hum., dan Dr. Dedi Koswara., M.Hum, Departemen Pendidikan Bahasa Sunda, 
Fakultas Pendidikan Bahasa dan Sastra, Universitas Pendidikan Indonesia yang sudah membimbing dalam menyusun jurnal ini. Semoga jurnal ini dapat bermanfaat dalam penelitian-penelitian selanjutnya. 
